\title{
WEB-DL Endovascular Treatment of Wide-Neck Bifurcation Aneurysms: Short- and Midterm Results in a European Study
}

B. Lubicz, J. Klisch, J.-Y. Gauvrit, I. Szikora, M. Leonardi, T. Liebig, N.P. Nuzzi, E. Boccardi, F.D. Paola, M. Holtmannspötter, W. Weber, E. Calgliari, V. Sychra, B. Mine, and L. Pierot

\begin{abstract}
BACKGROUND AND PURPOSE: Flow disruption with the WEB-DL device has been used safely for the treatment of wide-neck bifurcation aneurysms, but the stability of aneurysm occlusion after this treatment is unknown. This retrospective multicenter European study analyzed short- and midterm data in patients treated with WEB-DL.
\end{abstract}

MATERIALS AND METHODS: Twelve European neurointerventional centers participated in the study. Clinical data and pre- and postoperative short- and midterm images were collected. An experienced interventional neuroradiologist independently analyzed the images. Aneurysm occlusion was classified into 4 grades: complete occlusion, opacification of the proximal recess of the device, neck remnant, and aneurysm remnant.

RESULTS: Forty-five patients ( 34 women and 11 men) 35-74 years of age (mean, $56.3 \pm 9.6$ years) with 45 aneurysms treated with the WEB device were included. Aneurysm locations were the middle cerebral artery in 26 patients, the posterior circulation in 13 patients, the anterior communicating artery in 5 patients, and the internal carotid artery terminus in 1 patient. Forty-two aneurysms were unruptured. Good clinical outcome (mRS < 2) was observed in $93.3 \%$ of patients at the last follow-up. Adequate occlusion (complete occlusion, opacification of the proximal recess, or neck remnant) was observed in 30/37 patients (81.1\%) in short-term follow-up (median, 6 months) and in $26 / 29$ patients (89.7\%) in midterm follow-up (median, 13 months). Worsening of the aneurysm occlusion was observed in $2 / 28$ patients $(7.1 \%)$ at midterm follow-up.

CONCLUSIONS: The results suggest that the WEB endovascular treatment of wide-neck bifurcation aneurysms offers stable occlusion in a class of aneurysms that are historically unstable. Additionally, our data show that opacification of the WEB recess can be delineated from true neck or aneurysm remnants.

ABBREVIATIONS: WEB-DL = WEB Dual Layer; WEB-SL = WEB Single Layer; WEB-SLS = WEB Single Layer Sphere; CLARITY = Clinical and Anatomical Results in the Treatment of Ruptured Intracranial Aneurysms.

ndovascular treatment is now the first-line approach for both Eruptured and unruptured aneurysms. ${ }^{1-4}$ However, the limitations of standard coiling have contributed to the development of

\footnotetext{
Received October 17, 2013; accepted after revision December 5.
}

From the Department of Neuroradiology (B.L., B.M.), Erasme University Hospital, Brussels, Belgium; Department of Diagnostic and Interventional Radiology and Neuroradiology (J.K., V.S.), Helios General Hospital, Erfurt, Germany; Department of Neuroradiology (J.-Y.G.), Centre Hospitalier Universitaire Rennes, Rennes, France; Department of Neuroradiology (I.S.), National Institute of Neurosciences, Budapest, Hungary; Department of Neuroradiology (M.L.), Ospedale Bellaria, Bologna University, Bologna, Italy; Department of Neuroradiology (T.L.), Universitaetsklinikum Koeln, Cologne, Germany; Department of Neuroradiology (N.P.N.), Ospedale Galliera, Genova, Italy; Department of Neuroradiology (E.B.), Ospedale Niguarda, Milano, Italy; Department of Neuroradiology (F.D.P.), Ospedale Santa Maria, Treviso, Italy; Department of Neuroradiology (M.H.), Rigshospitalet, Copenhagen, Denmark; Department of Neuroradiology (W.W.), Knappschaftskrankenhaus, Recklinghausen, Germany; Department of Neuroradiology (E.C.), Ospedale dell'Angelo, Mestre, Italy; and Department of Neuroradiology (L.P.), Hôpital Maison-Blanche, Université Reims-Champagne-Ardenne, Reims, France.

Please address correspondence to Laurent Pierot, MD, Service de Radiologie-Hôpital Maison-Blanche, 45, rue Cognacq-Jay, 51092 Reims cedex, France; e-mail: Ipierot@gmail.com new endovascular approaches, including balloon-assisted coiling, stent-assisted coiling, flow diversion, and flow disruption. ${ }^{5}$

The WEB (Sequent Medical, Aliso Viejo, California) is an intrasaccular device designed to disrupt the intra-aneurysmal flow at the level of the neck. ${ }^{6-9}$ Several devices are now available in the WEB family: WEB-DL and the more recently introduced WEB-SL and WEB-SLS. Initial experience with the WEB-DL has shown the clinical utility of this device in wide-neck bifurcation aneurysms with high technical success and low acute morbidity and mortality. ${ }^{7-9}$ Also, the initial WEB-DL literature suggests good efficacy, with a high percentage of adequate occlusion (complete occlusion or neck remnant) in the postoperative period and in short-term follow-up. In the largest series, a significant number of neck remnants were observed at follow-up (56.7\%). ${ }^{9}$ This was due, in part,

\footnotetext{
-- Indicates open access to non-subscribers at www.ajnr.org

Evidence-Based Medicine Level 2.

http://dx.doi.org/10.3174/ajnr.A3869
} 
to the shape of the WEB-DL. The proximal surface of the WEB-DL is not flat but has a recess, which is concave from the direction of the parent artery. The WEB-DL and its recess conform to the aneurysm on the basis of the physician's WEB-DL size choice. For example, the physician may choose to minimize the WEB-DL parent vessel protrusion by allowing the recess to form within the aneurysm sac; however, this contributes to the appearance of a neck remnant, though this remnant is located centrally and proximally relative to the WEB-DL. Alternatively, with a different WEB-DL size choice, the recess can be removed and the proximal portion of the WEB-DL resides in the neck/parent vessel interface as a flow divider.

Aneurysm coil recanalization is an important issue in endovascular therapy, with approximately $20 \%$ of coiled aneurysms recanalized and $10 \%$ retreated. ${ }^{10}$ As previously shown, wide-neck aneurysms are highly prone to recanalization. ${ }^{11}$

The goal of this retrospective, multicenter, European study was to analyze the midterm clinical outcome, short- (3-8 months) and midterm ( $\geq 9$ months) anatomic results after WEB-DL aneurysm treatment, and the stability of the treatment as well as the rate of retreatment. A point of particular interest was to determine whether the opacification of the proximal recess was stable with time or was a feature promoting aneurysm recanalization.

\section{MATERIALS AND METHODS \\ Population}

The study received institutional review board approval, and according to the design of the trial, informed consent was waived. European neurointerventional centers were selected if the center treated at least 1 patient with the WEB-DL and the treatment occurred 1 year before the data collection cutoff date (May 2013). Twelve European centers participated in the study. In these centers, a total of 67 patients were treated at least 1 year before the cutoff date.

\section{WEB-DL Device}

The self-expanding WEB-DL is a globular, braided nitinol mesh. The device is composed of inner and outer braids held together by proximal, middle, and distal radiopaque markers. The WEB-DL implant is deployed — or retrieved before detachment—in a manner similar to that of conventional endovascular coil systems by using microcatheters with an internal diameter of $\geq 0.027$ inches (WEB-DL width between 5 and $8 \mathrm{~mm}$ ) or $\geq 0.032$ inches (WEB-DL width between 9 and $11 \mathrm{~mm}$ ). Once the device is deployed, it is fully retrievable. If a satisfactory position is achieved, electrothermal detachment is instantaneous. New WEB singlelayer devices, in 2 shapes, were recently developed and introduced in the European market (WEB-SL and WEB-SLS), but they were not used in this series.

\section{Procedural Modalities}

In each institution, the indication for treatment and its technique (surgery or endovascular treatment) was decided on a case-bycase basis by a local multidisciplinary team, including neurosurgeons, neuroanesthesiologists, neurologists, and neuroradiologists. The selection of aneurysms treated with the WEB-DL device was performed autonomously in each center by the interventional neuroradiologists according to aneurysm characteristics (aneurysm status, aneurysm location and size, neck size).

Aneurysms were treated with the WEB-DL by using techniques similar to those used in the treatment of aneurysms with coils (eg, general anesthesia, intraoperative treatment with intravenous heparin, single or double femoral approach). Pre-, intra-, and postoperative antiplatelet therapy was managed in each center as indicated for typical endovascular treatment with coils (or stent and coils if this approach was a potential alternative treatment).

After accurate evaluation of aneurysm anatomy (aneurysm morphology, aneurysm transverse diameter and height, and neck size) by the treating physician using MR angiography and digital subtraction angiography, whether the treatment with WEB-DL was indicated and the appropriate device sizing were determined.

After positioning a guiding catheter into the internal carotid artery or vertebral artery, we catheterized the aneurysm by using a microcatheter and chose the WEB-DL size according to aneurysm measurements and positioned it in the aneurysmal sac per methods described in Pierot et al (2013). ${ }^{9}$ A control angiogram was obtained to check the position of the device in the aneurysm and to evaluate flow stagnation inside it. XperCT (Philips Healthcare, Best, the Netherlands) and DynaCT (Siemens, Erlangen, Germany) are complementary acquisitions produced by a flat panel detector, which facilitate the visualization of the device after deployment because it is not completely visible on fluoroscopy. However, these were only used in a limited number of patients in the present series. If the position was not satisfactory, the device was resheathed and repositioned. If the size was not appropriate, the device was resheathed and another device was deployed into the aneurysm. When the right-sized device was correctly positioned, a final DSA run was performed. Treatment with ancillary devices (balloon, coils, and stent) was performed if deemed necessary by the treating physician.

\section{Data Collection}

Each center completed a patient file with the following data: patient age and sex, aneurysm status (ruptured/unruptured), aneurysm characteristics including location classified into 4 groups (internal carotid artery, middle cerebral artery, posterior circulation, anterior communicating artery), size and neck size, date of the procedure, occurrence of a complication during or after the procedure, use of an additional device during the procedure (coils, remodeling balloons, stents, or flow diverters), and modified Rankin Scale score at discharge and at last follow-up.

Pre- and postoperative short-term (3-8 months) and midterm images (at least 9 months) were collected. For DSA, frontal, lateral, and working views were collected as well as 3D angiography when available. For MRA and CT angiography, frontal, lateral, and working-view reconstructions were collected. MRA or CTA examinations were used exclusively when DSA was not performed.

\section{Data Analysis}

The collected patients included those from the earliest WEB-DL clinical experience (first patient treated in October 

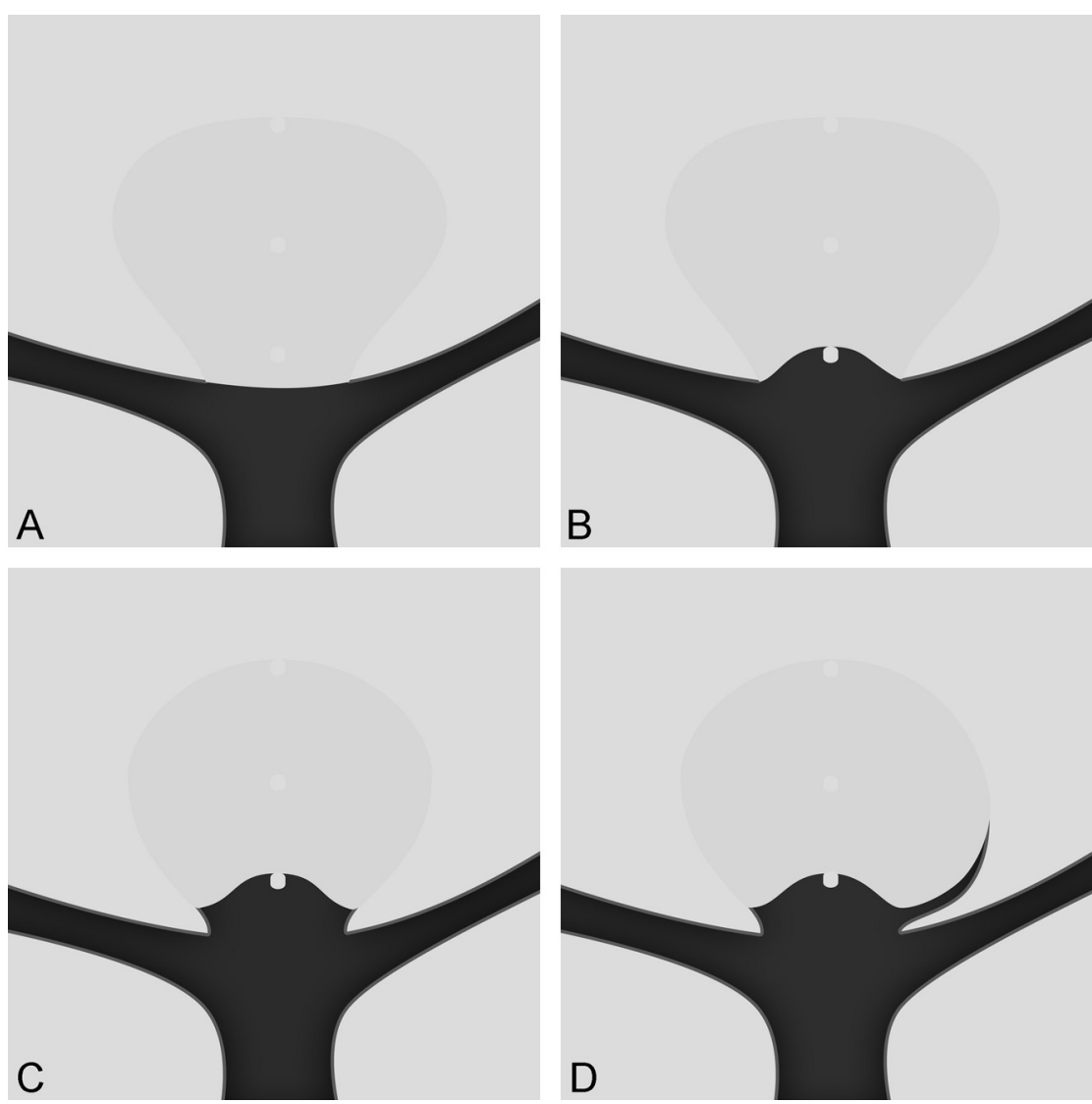

FIG 1. The drawings show the scale used for the anatomic results. A, Complete occlusion (grade A). There is no contrast inside the aneurysm. $B$, Complete occlusion with opacification of the proximal recess (grade $A B$ ). There is no contrast inside the aneurysm but contrast fills in the central area below the WEB-DL. C, Neck remnant (grade B). There is contrast at the aneurysmal wall but no contrast in the aneurysm or WEB-DL. D, Aneurysm remnant (grade C). There is contrast in the neck and in the aneurysm or WEB-DL.

\section{RESULTS}

Patient and Aneurysm Populations

Between October 2010 and May 2012, sixty-seven patients with 67 aneurysms were treated with the WEB-DL device in the 12 participating centers. According to the criteria defined in "Materials and Methods," 22 patients with 22 aneurysms were excluded for the following reasons: neck of $<4 \mathrm{~mm}$ in 11 patients, aneurysm not located at a bifurcation in 4 patients, aneurysm size of $>12 \mathrm{~mm}$ in 3 patients, and partially thrombosed aneurysms in 2 patients. Two other patients were excluded due to the lack of clinical information.

Finally, the population of the study was 45 patients ( 34 women and 11 men), 35-74 years of age (mean, $56.3 \pm 9.6$ years), with 45 aneurysms treated with the WEB-DL device.

Aneurysm locations were the MCA in 26 patients, posterior circulation in 13 patients (including 11 patients with basilar artery aneurysms and 2 with posterior inferior cerebellar artery aneurysms), anterior communicating artery in 5 patients, and ICA terminus in 1 patient. Three aneurysms were ruptured, and 42 were unruptured. Aneurysm size was $<5 \mathrm{~mm}$ in 5 patients, $5-10 \mathrm{~mm}$ in 38 patients, and $>10$ $\mathrm{mm}$ (and $<12 \mathrm{~mm}$ ) in 2 patients.
2010), which did not have the benefit of the procedural and device learning curve. Therefore, to evaluate the anatomic results in a homogeneous population with typical indications for WEB-DL, the patients were included if their aneurysm met the following criteria:

- Located at a bifurcation: ICA, MCA, anterior communicating artery, basilar artery, posteroinferior cerebellar artery

- Nonthrombosed

- With a wide neck ( $\geq 4 \mathrm{~mm}$ )

- With a maximum diameter of $\leq 12 \mathrm{~mm}$.

An independent reader who has experience with the WEB-DL but with no patient in the present series (J.-Y.G.) analyzed the images (pre- and postoperative and short-term and midterm follow-up) by using a 4-grade scale: complete occlusion, complete occlusion with opacification of the proximal recess of the device, neck remnant, and aneurysm remnant. He also analyzed the evolution of aneurysm occlusion between short- and midterm follow-up and classified it as improved, stable, or worsened.

Clinical data were reviewed by the 2 principal investigators of the study (B.L. and L.P.), who requested further clinical data if necessary.

\section{Treatment Modalities}

The treatment was conducted in a standard way in 38 patients with 1 device deployed in the aneurysm. In 1 patient, 2 WEB-DL devices were deployed in the aneurysm due to the aneurysm shape. In 4 patients, stent placement was used as an additional treatment due to WEB-DL protrusion (3 patients) and to thromboembolic complication treated with abciximab and stent (1 patient). One patient had an additional treatment with coils, and one, with coils and glue (see below).

\section{Technical Issues, Complications, and Clinical Outcome}

In 1 patient with a basilar artery aneurysm, a premature detachment of the device was observed when attempting to retrieve it because it was not an appropriate size. The device was easily removed by using standard maneuvers.

Four thromboembolic complications were observed during the treatment with the WEB-DL and were treated with intra-arterial administration of rtPA in 1 patient, IV administration of eptifibatide in 1 patient, IV abciximab and stent in 1 patient, and IV abciximab in 1 patient. In these 4 patients, the mRS score at discharge was 0 in 2 patients, 1 in 1 patient, and 2 in 1 patient. At last follow-up, the mRS score was 0 in 3 patients and 1 in 1 patient.

One patient with an MCA aneurysm had an intraoperative 
rupture. The WEB-DL was deployed in a daughter sac, which was ruptured. The rupture was treated with coils and glue, and 1 branch of the MCA bifurcation was occluded, inducing an MCA infarct. The patient had an mRS score of 3 at discharge and last follow-up. This case was already published in Lubicz et al. ${ }^{8}$

One patient with multiple aneurysms was treated successfully with the WEB-DL for a large symptomatic posterior inferior cerebellar artery aneurysm, but 4 months after the WEB-DL procedure, the patient underwent surgical clipping of an MCA aneu-
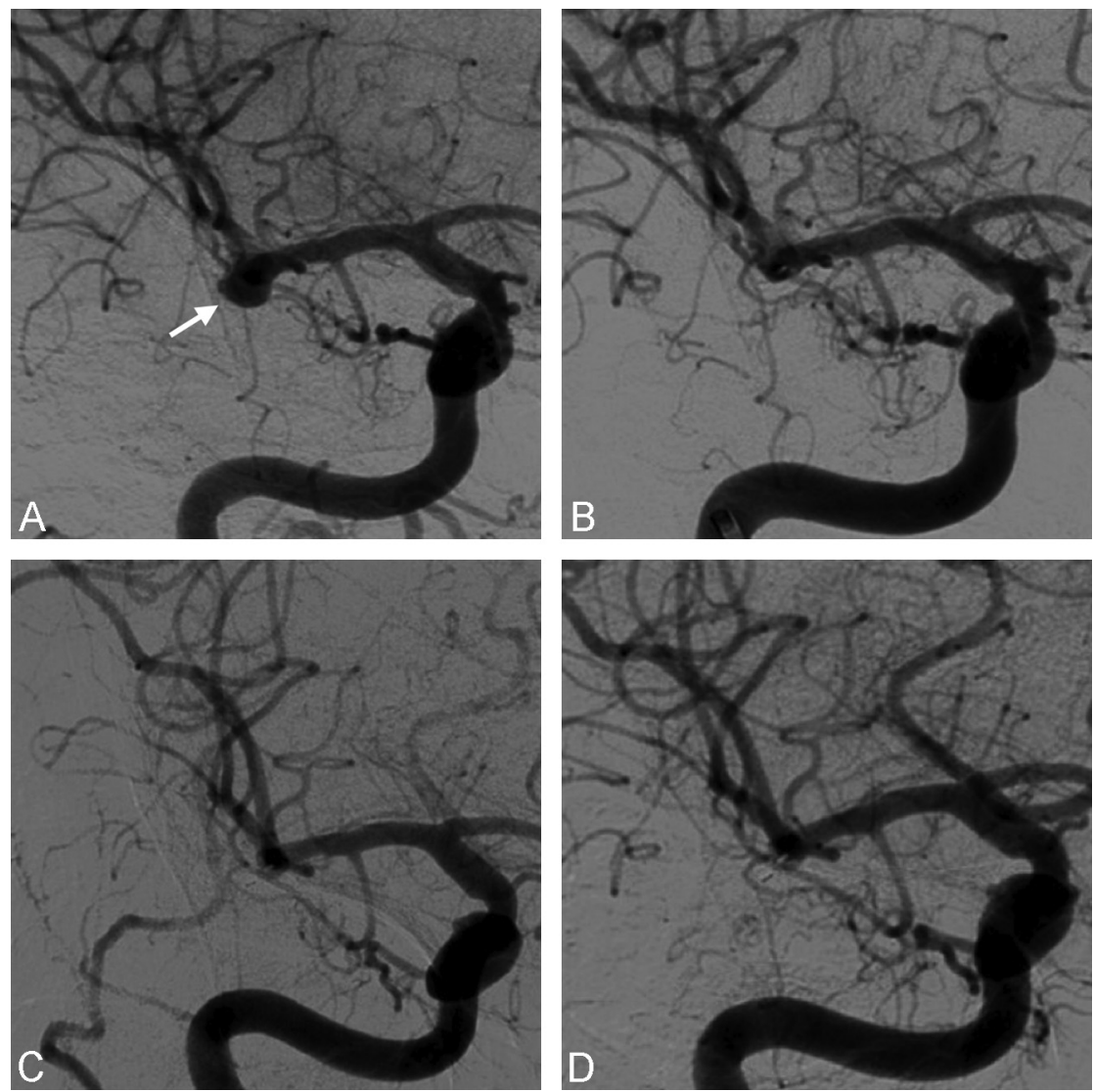

FIG 2. A 71-year-old woman with an unruptured right MCA. A, Preoperative DSA shows the wide-neck MCA aneurysm.. B, Postoperative DSA shows no more intra-aneurysmal flow. C, Sixmonth follow-up DSA shows the complete occlusion of the aneurysm. $D$, Twelve-month follow-up DSA shows the stability of the complete occlusion.
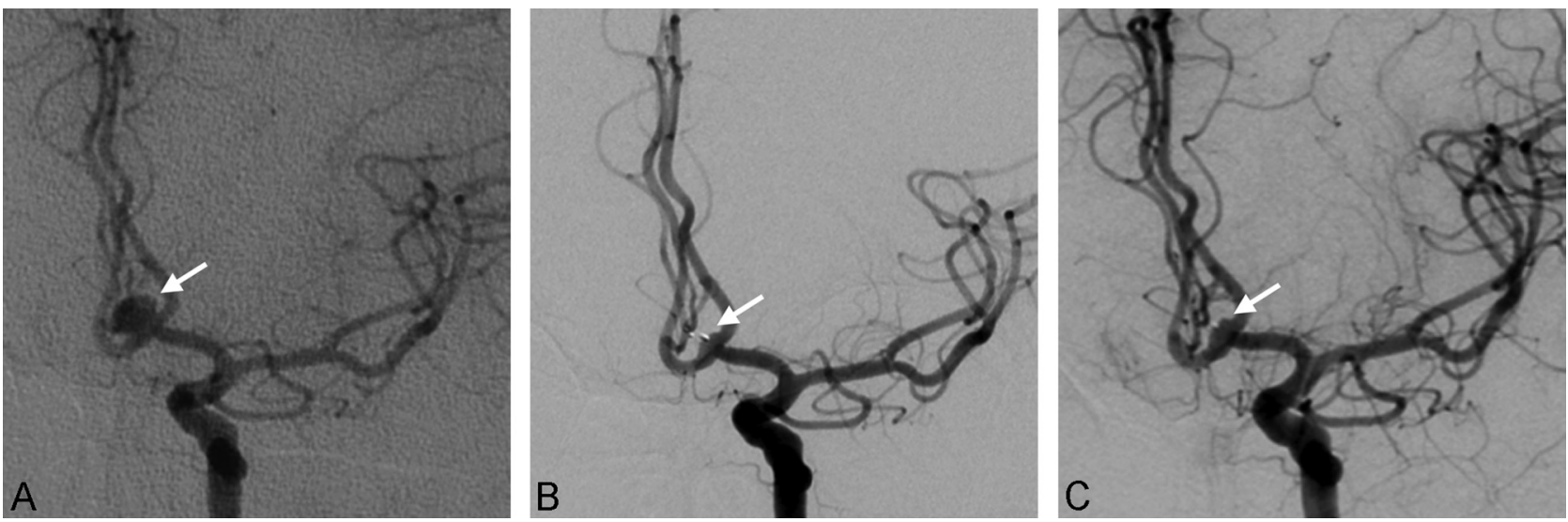

FIG 3. A 57-year-old man with an unruptured anterior communicating artery aneurysm. $A$, Preoperative DSA shows the wide-neck anterior communicating artery aneurysm. B, Six-month DSA shows an opacification of the proximal recess of the device. C, Twelve-month DSA shows the stability of this opacification. 

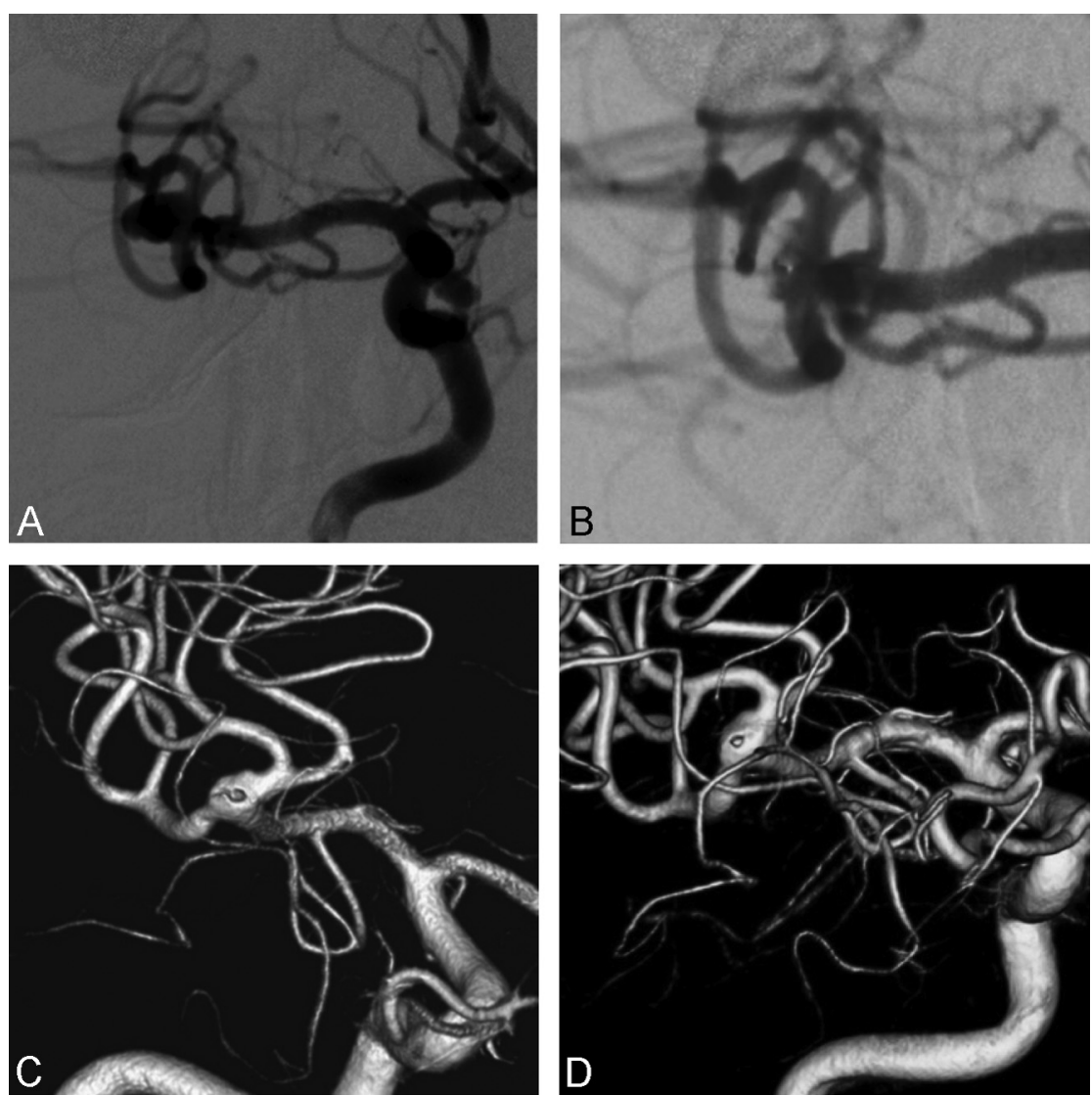

FIG 4. A 71-year-old woman with an unruptured right MCA aneurysm. A, Preoperative DSA shows the MCA aneurysm with a wide neck. $B$, Postoperative DSA shows a small residual opacification of the aneurysm neck with complete disappearance of flow in the dome. C, Seven-month 3D-DSA shows an opacification of the proximal recess of the device. D, Twelve-month 3D-DSA shows that this opacification is quite stable.

complication occurred intraoperatively in the left P1 segment and was treated with abciximab and stent placement. At 3 months, the aneurysm remnant was depicted, and it was retreated at 5 months with stent and coils. In a 39-year-old man, a wide-neck 7-mm MCA aneurysm recanalized 2 months after the treatment with an undersized (in height) WEB-DL. The aneurysm remnant was treated with coils 2 months after the initial treatment.

\section{Short-Term Anatomic Outcome}

Because the goal of the study was to evaluate the quality and stability of aneurysm occlusion after WEB-DL treatment, the 6 patients with additional coiling and/or stent placement were not included in the evaluation. One patient had no short-term follow-up imaging, and 1 patient died (see above). Finally, 37/45 patients $(82.2 \%)$ were evaluated in the short-term. Short-term follow-up was obtained from 2 to 8 months after the initial treatment (mean, $5.0 \pm 2.3$ months; median, 6 months). Modalities of short-term follow-up were DSA in 33 patients, MRA in 3 patients, and CTA in 1 patient.

Complete aneurysm occlusion was obtained in 9/37 patients (24.3\%) (Fig 1); opacification of the proximal recess with complete occlusion of the aneurysm, in $12 / 37$ patients (32.4\%) (Figs 2 and 3); neck remnant, in 9/37 patients (24.3\%) (Figs 4 and 5); and aneurysm remnant, in 7/37 patients (18.9\%). Adequate occlusion (complete occlusion, opacification of the proximal recess, or neck remnant) was observed in $30 / 37$ patients $(81.1 \%)$.

\section{Midterm Anatomic Outcome}

Because the goal of the study was to evaluate the quality and stability of aneurysm occlusion after WEB-DL treatment, 9 patients with additional coiling and/or stent placement or retreatment were not included in the evaluation (1 patient had both additional treatment and retreatment). One patient died (see above), and 6 patients refused midterm follow-up examinations. Finally, 29/45 patients $(64.4 \%)$ were evaluated in the midterm. Midterm follow-up was obtained from 9 to 28 months after the initial treatment (mean, $14.3 \pm 7.0$ months; median, 13 months). Modalities of midterm follow-up were DSA in 22 patients and MRA in 7 patients.

Complete aneurysm occlusion was obtained in $8 / 29$ patients (27.6\%); opacification of the proximal recess with complete occlusion of the aneurysm, in $12 / 29$ patients $(41.4 \%)$; neck remnant, in $6 / 29$ patients $(20.7 \%)$; and aneurysm remnant, in $3 / 29$ patients $(10.3 \%)$. Adequate occlusion (complete occlusion, opacification of the proximal recess, or neck remnant) was observed in $26 / 29$ patients $(89.7 \%)$.

\section{Evolution between Short- and Midterm Follow-Up}

Among the 29 patients with midterm follow-up, 1 had no shortterm follow-up. Thus, the evolution of aneurysm occlusion was evaluable in 28 patients. In $26 / 28$ patients ( $92.9 \%$ ), aneurysm occlusion was stable (Fig 1). In 2/28 patients (7.1\%) with neck remnants at 3 months, a worsening of the aneurysm occlusion was observed in midterm follow-up, with an aneurysm remnant in both cases (Fig 5).

All patients with opacification of the proximal recess at 3-6 months had a stable aneurysm occlusion at midterm follow-up (Figs 2 and 3).

\section{DISCUSSION}

Our retrospective study analyzed the midterm clinical outcome, and the short- and midterm results of the first WEB-DL-treated patients with wide-neck, bifurcation intracranial aneurysms in 12 European centers. This study included patients treated during the individual and global procedure/device learning curve; however, the data suggest several interesting aspects of WEB-DL intrasaccular flow disruption.

Overall the midterm clinical follow-up showed a very high rate of patients with good clinical outcome (93.3\%), given that 1 patient had an mRS score of 3 due to surgical treatment of another aneurysm. This good midterm clinical outcome confirms what 

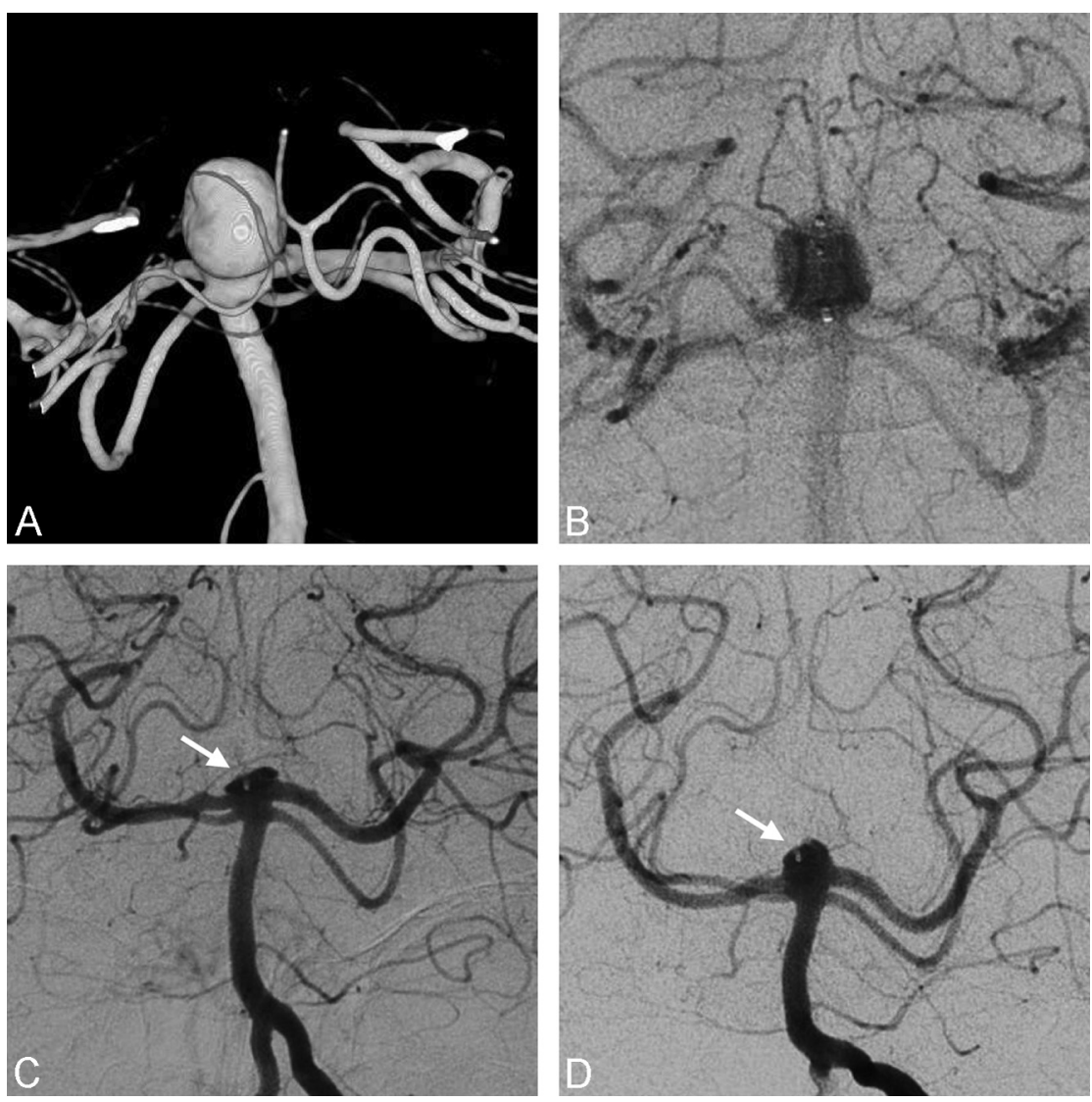

FIG 5. A 60-year-old woman with an unruptured basilar artery aneurysm. A, Preoperative 3DDSA shows the aneurysm, which is wide-neck. $B$, Postoperative DSA shows contrast stagnation in the WEB and aneurysm; C, 3-month DSA shows a neck remnant. D, 9-month DSA shows the reopening of the aneurysm with a remnant.

was observed in previous WEB-DL series and compares favorably with outcomes of other sophisticated techniques like stent placement and flow diversion. ${ }^{7-9,12-14}$

At the beginning of the global experience with WEB-DL, indications for treatment with the WEB-DL device were not precisely known and some aneurysms were initially treated that are now not typically treated with the WEB-DL device. Anatomic results were analyzed in patients with aneurysms that are now typical indications for WEB-DL (wide-neck, bifurcation aneurysms with an average width of $>4 \mathrm{~mm}$ but $<12 \mathrm{~mm}$ ).

Because this series reflects the initial experience with the device, it is clear that the physicians had no technical experience and may have made some technical errors, for example in the sizing of the device, which is an important issue, likely explaining the rate of additional treatments performed during the initial procedures as well as the rate of retreatment observed in the months following the initial treatment. To accurately analyze the efficacy of the WEB-DL device alone, patients with aneurysms treated with WEB-DL and additional treatment were not included in the analysis of the anatomic results. For the same reason, patients with aneurysms retreated during the follow-up period were not included in the anatomic analysis.

The present series shows that in this group of complex wideneck bifurcation aneurysms, appropriate occlusion was obtained in a high percentage of cases in the short- $(81.1 \%)$ and midterm $(89.7 \%)$ results. The treatment was quite stable with time, with worsening of the occlusion status in only $7.1 \%$ between short- and midterm follow-up. Most important, all aneurysms with opacification of the proximal recess at short-term follow-up had stable occlusion at midterm follow-up.

As was previously shown, neck size is a critical factor for aneurysm recanalization and midterm anatomic results in aneurysms treated with coils. In the Clinical and Anatomical Results in the Treatment of Ruptured Intracranial Aneurysms (CLARITY) study-dealing with ruptured aneurysms-aneurysm neck size was identified as the single most important factor in the quality of aneurysm occlusion at midterm follow-up after standard endovascular treatment. ${ }^{11}$ In this series, adequate occlusion was obtained in the whole population (narrow and wide-neck aneurysms) in $80.4 \%$ at midterm follow-up after bare platinum coil treatment. In wide-neck aneurysms, the rate of adequate occlusion was $68.2 \%$, which is much lower than the $89.7 \%$ observed in the present series. Also in the review of Ferns et $\mathrm{al}^{10}$ dealing with narrow and wide-neck aneurysms, the rate of adequate occlusion at follow-up was only $83.4 \%$, lower than the percentage in the

present series.

With WEB-DL treatment, aneurysm occlusion was stable (between short- and midterm follow-ups) in most aneurysms (92.9\%), and worsening of aneurysm occlusion was observed in only $7.1 \%$ of cases. Worsening was exclusively observed in aneurysms with a neck remnant at short-term follow-up. In the CLARITY study, ${ }^{11}$ worsening of aneurysm occlusion was observed in $51.1 \%$ of aneurysms in the whole group and in $62.1 \%$ in wide-neck aneurysms. Most interesting, the specific pattern "complete occlusion with opacification of the proximal recess" was not modified between short- and midterm follow-up, and it can be considered complete aneurysm occlusion.

The rate of retreatment in the present series (8.9\%) is slightly higher than that reported in CLARITY $(6.2 \%),{ }^{11}$ but it was slightly lower than that calculated in the Ferns et al review $(10.3 \%) .{ }^{10}$ As previously mentioned, the present series dealt with the first cases treated in the 12 participating centers and clearly during the learning curve. In 2 retreatments, the WEB-DL device was undersized in the initial treatment; this result clearly reflected the lack of experience. In 2 other complex aneurysms, retreatment with coils was initially planned, with the WEB-DL device being used to modify the shape of the neck. Because these 2 cases are not true retreatments, the retreatment rate is, in fact, 2/45 aneurysms (4.4\%), which is quite acceptable in the specific population of the series.

Our study has several limitations. First, the series is retrospec-

AJNR Am J Neuroradiol 35:432-38 Mar 2014 www.ajnr.org 
tive and has a limited number of patients $(n=45)$, and midterm follow-up was not available for all (29/45). However, because it is a new endovascular treatment, it was important to have a rapid and accurate preliminary evaluation of the quality and stability of aneurysm occlusion in the midterm. A second limitation is that short- and midterm anatomic evaluations were conducted by using different modalities (mostly DSA and MRA). However, recent publications confirm the value of MRA in the follow-up of intracranial aneurysms. ${ }^{15,16} \mathrm{~A}$ third limitation is that only the WEB-DL (and not WEB-SL and WEB-SLS) was evaluated.

\section{CONCLUSIONS}

In this series dedicated to clinical and anatomic follow-up of complex, wide-neck bifurcation aneurysms, treatment with the WEB-DL was associated with a high rate of good clinical outcome (93.3\%) and appropriate occlusion in short- and midterm followups (respectively, $81.1 \%$ and $89.7 \%$ ) and limited worsening of the aneurysm occlusion between short- and midterm follow-ups (7.1\%). Opacification of the proximal recess was not associated, in short- or midterm follow-up, with aneurysm recanalization and can be grouped with "complete occlusion." Moreover, the presence of the WEB-DL recess can be delineated from true neck remnant and/or true aneurysm remnant by its central and proximal location relative to the WEB-DL.

Disclosures: Boris Lubicz-RELATED: Consulting Fee or Honorarium: Sequent Medical, Payment for Writing or Reviewing the Manuscript: Sequent Medical, UNRELATED: Consultancy: Codman, MicoVention, Covidien, Payment for Manuscript Preparation: Sequent Medical, Payment for Development of Educational Presentations: Codman.* Joachim Klisch—RELATED: Consulting Fee or Honorarium: Sequent.* Istvan Szikora-RELATED: Provision of writing assistance, medicines, equipment, or administrative support: Sequent Medical,* Comments: no money paid, some products provided free of charge, UNRELATED: Consultancy: Stryker Neurovascular, Codman, Covidien, Payment for Lectures (including service on Speakers Bureaus): Stryker Neurovascular, Codman. Thomas Liebig-UNRELATED: Consultancy: Stryker, Covidien, Sequent Medical, Comments: consulting fee regarding preclinical work and proctoring the product, Payment for Lectures (including service on Speakers Bureaus): Stryker, Sequent Medical, Comments: payment for lecturing in satellite symposia. Nunzio Paolo Nuzzi-RELATED: Consulting Fee or Honorarium: Sequent Medical, Comments: proctor for WEB clinical use, UNRELATED: Consultancy: Covidien, Comments: proctor for clinical use of Pipeline Embolization Device. Markus Holtmannspötter-UNRELATED: Consultancy: Covidien, MicroVention, Sequent Medical, Comments: proctoring and consulting fees; Payment for Lectures (including service on Speakers Bureaus): Covidien, MicroVention, Sequent Medical. Werner Weber-UNRELATED: Other: Sequent Medical, Comments: I am a proctor for the WEB device, and our institution is participating on the WEB Clinical Assessment of IntraSaccular Aneurysm Therapy study. * Laurent PierotRELATED: Consulting Fee or Honorarium: Sequent, UNRELATED: Consultancy: Codman, Covidien, MicroVention, Penumbra. *Money paid to the institution.

\section{REFERENCES}

1. Molyneux A, Kerr R, Stratton I, et al, for the International Subarachnoid Aneurysm Trial (ISAT) Collaborative Group. International Subarachnoid Aneurysm Trial (ISAT) of neurosurgical clipping versus endovascular coiling in 2143 patients with ruptured intracranial aneurysms: a randomised trial. Lancet 2002;360:1262-63

2. Mc Dougall CG, Spetzler RF, Zabramski JM, et al. The Barrow Ruptured Aneurysm Trial. J Neurosurg 2012;116:135-44

3. Cognard C, Pierot L, Anxionnat R, et al. Results of embolization used as the first treatment choice in a consecutive non selected population of ruptured aneurysms: clinical results of the CLARITY GDC study. Neurosurgery 2011;69:837-41

4. Pierot L, Spelle L, Vitry F, for the ATENA investigators. Clinical outcome of patients harbouring unruptured intracranial aneurysms treated by endovascular approach: results of the ATENA trial. Stroke 2008;39: 2497-504

5. Pierot L, Wakhloo A. Endovascular treatment of intracranial aneurysms: current status. Stroke 2013;44:2046-54

6. Ding YH, Lewis DA, Kardivel R, et al. The Woven EndoBridge: a new aneurysm occlusion device. AJNR Am J Neuroradiol 2011;32:607-11

7. Pierot L, Liebig T, Sychra V, et al. Intrasaccular flow-disruption treatment of intracranial aneurysms: preliminary results of a multicenter clinical study. AJNR Am J Neuroradiol 2012;33:1232-38

8. Lubicz B, Mine B, Collignon L, et al. WEB device for endovascular treatment of wide-neck bifurcation aneurysms. AJNR Am J Neuroradiol 2013;34:1209-14

9. Pierot L, Klisch J, Cognard C, et al. Middle cerebral artery aneurysms: feasibility, clinical and anatomical results of the endovascular treatment by WEB flow disruption: preliminary evaluation in a multicenter study. Neurosurgery 2013;73:27-34

10. Ferns SP, Sprengers ME, van Rooij WJ, et al. Coiling of intracranial aneurysms: a systematic review on initial occlusion and reopening and retreatment rates. Stroke 2009;40:e523-e529

11. Pierot L, Cognard C, Anxionnat R, et al. Endovascular treatment of ruptured intracranial aneurysms: factors affecting mid-term quality anatomic results — analysis in a prospective multicenter series of patients (CLARITY). AJNR Am J Neuroradiol 2012;33:1475-80

12. Shapiro M, Becske T, Sahlein, et al. Stent-supported aneurysm coiling: a literature survey of treatment and follow-up. AJNR Am J Neuroradiol 2012;33: 159-63

13. Pierot L. Flow diverter stents in the treatment of intracranial aneurysms: where are we? J Neuroradiol 2011;38:40-46

14. Becske T, Kallmes DF, Saatci I, et al. Pipeline for uncoilable or failed aneurysms: results from a multicenter clinical trial. Radiology 2013;267:858-68

15. Pierot L, Portefaix C, Gauvrit JY, et al. Follow-up of coiled intracranial aneurysms: comparison of $3 \mathrm{D}$ time-of-flight at $3 \mathrm{~T}$ and $1.5 \mathrm{~T}$ in a large, prospective series. AJNR Am J Neuroradiol 2012;33:2162-66

16. Pierot L, Portefaix C, Boulin A, et al. Follow-up of coiled intracranial aneurysms: comparison of 3D-time-of-flight and contrast-enhanced magnetic resonance angiography at $3 \mathrm{~T}$ in a large, prospective series. Eur Radiol 2012;22:2255-63 
The authors apologize and state that in the original article "WEB-DL Endovascular Treatment of Wide-Neck Bifurcation Aneurysms:

Short- and Midterm Results in a European Study” by B. Lubicz, J. Klisch, J.-Y. Gauvrit, I. Szikora, M. Leonardi, T. Liebig, N.P. Nuzzi,

E. Boccardi, F.D. Paola, M. Holtmannspötter, W. Weber, E. Calgliari, V. Sychra, B. Mine, and L. Pierot [AJNR Am J Neuroradiol 2014;35:432-38, 10.3174/ajnr.A3869], there is an error in the author affiliations of Prof. M. Leonardi (M.L.). The correct version is given below.

Department of Neuroradiology (M.L.), Ospedale Bellaria, IRCCS Istituto delle Scienze Neurologiche di Bologna and DIMES, Department of Specialty, Diagnostic and Experimental Medicine, University of Bologna, Bologna, Italy.

http://dx.doi.org/10.3174/ajnr.A4250 